\title{
Power Quality Enhancement of Three Phase Four Wire UPQC in Distribution System using Neural Network
}

\author{
J Shravani, G. Deva Dasu
}

\begin{abstract}
The essential focus of this endeavor is examination of three phase four wire UPQC available for use structures by neural framework. The bound together power-quality conditioner (UPQC) is used to calm the current and voltage-related power-quality $(P Q)$ issues in the meantime in three-arrange four-wire course structures. Among most of the PQ issues, voltage hang is a significant issue in three-arrange four-wire scattering systems. In this paper, another procedure is proposed playing out the plan parallel electrical cable trim. As such, despite when only a three-organize three-wire control structure is available at a plant site, the UPQC can do control line pay for presented loads that require a fair-minded channel to work. Not exactly equivalent to the control philosophies used in most of UPQC applications in which the controlled sums are nonsinusoidal, this UPQC uses a twofold pay technique, with the ultimate objective that the controlled sums are continually sinusoidal. Neural System controller have been used to make the proposed methodology online for least real power implantation with UPQC by using the PSObased data for different voltage rundown conditions. In the proposed system PI controller substituted by NN controller for better precision.
\end{abstract}

Index Terms- Active filter, dual control strategy, UPQC, Neural networks.

\section{INTRODUCTION}

The enthusiasm for power quality (PQ) improvement has been creating starting late, fundamentally due to the development of nonlinear weights related with the electrical power structure causing twists in the utility voltages at the motivation behind essential coupling. Other PQ issues, for instance, voltage hangs/swells and voltage unbalances can moreover impact the most ideal undertaking of tricky equipment causing breakdown. In addition, additional philosophy should be considered in order to overcome PQ issues related with consonant flows delivered by nonlinear weights, load unbalances and responsive power mentioned by the pile.

A couple of strategies have been grasped to assuage PQ issues, which should be possible by techniques for dynamic electrical cable conditioners, for instance, UPQCs course of action [25] and hybrid unique power stations (APFs) and dynamic voltage restorers

In three-arrange systems, they should be used for compensating consonant flows [20] or burden unbalances

Revised Version Manuscript Received on August 19, 2019.

J Shravani, PG Scholar, Department of EEE, CMR College of Engineering \& Technology, Kandlakoya, Hyderabad, Telangana, India. (email: shravanichinni03@gmail.com)

G. Deva Dasu, Head of the Department, EEE, CMR College of Engineering \&Technology, Kandlakoya, Hyderabad, Telangana, India. (email: gdevadas10@gmail.com) and weight responsive power pay [21]-[24]. Filling in as nonsinusoidal voltage sources or sinusoidal current sources

course of action APF channels, which are set between the utility cross section and the stack, can compensate consonant flows, load unbalances and responsive intensity of the store, while the pile voltages are controlled. Thusly, for vanquishing utility PQ issues, UPQCs have been used reliant on different thoughts and courses of action [10], [13], [15], including single-organize structures [14] or in three-arrange applications, pondering three-arrange three-wire (3P3W) frameworks or three-organize four-wire (3P4W) systems [11], [12].

It is excellent that non-sinusoidal references are hard to be composed by PWM converters and require an extra exertion to accomplish exceptional execution in APF or UPQC applications. Then again, sinusoidal control references have been utilized in applications including uninterruptible power supply (UPS) structures with the ultimate objective that in the reinforcement movement mode the UPS system acts additionally to an UPQC playing out the game plan parallel power compensation. In this application, the plan converter is controlled to fill in as a sinusoidal current source rather than a non-sinusoidal voltage source, while in the parallel embellishment the parallel converter is controlled to function as a sinusoidal voltage source instead of a non-sinusoidal current source.

In addition, this twofold pay framework has also been attempted in UPQC applications [2][4]. Thusly, not exactly equivalent to the standard embellishment framework, which uses non-sinusoidal control references, the twofold compensating methodology uses simply sinusoidal references to control the PWM converters. Appropriately, the age of the control references is more straightforward to obtain, empowering the usage of simpler computations to accomplish this point.

It might be seen that, since the parallel converter is controlled to manage simply sinusoidal voltages [2], [3], the utility voltage parts that are not equivalent to the positive gathering portions will appear over the course of action coupling transformers, so they are in an indirect manner reimbursed without the need to register any non-sinusoidal compensation reference voltages..

Synchronous Reference Edge (SRF) based controller are executed in this paper to control the data flows and the yield voltages of the UPQC. Inciting a reduction in steadfast state botches when normal Relative 


\section{Power Quality Enhancement of Three Phase Four Wire UPQC in Distribution System using Neural Network}

Indispensable (PI) controllers are picked to be executed in this equal reference plot, addressing another critical piece of elbowroom when the two fold compensation system is stood out from the standard one. The UPQC input flows are moreover controlled to be in stage with the utility voltages.

As such, the assessed utility stage edge $(\theta)$ got from the PLL is moreover used to deliver the sinusoidal information current references. At the point when the common 3pPLL suffers with utility voltage agitating impacts, for instance, sounds just as unbalances, a self-tuning channel (STF) [23] is used identified with the 3pPLL arrangement. The STF is set between the utility voltages and the 3pPLL arrangement, where the dapper repeat assessed from the 3pPLL is used to adjust the STF cut-off repeat, avoiding that assortments in utility repeat can interfere or impact its introduction. In [27] Devadasu et.al discussed the IDVR for power quality issues. Malathi et.al [28] discussed custom power devices for PQ improvement.

The guideline responsibility of this paper is to display the rational execution of a 3P4W apportionment structure reliant on UPQC topology, which has been as of late evaluated in [6] using diversions. Along these lines, if only a $3 \mathrm{P} 3 \mathrm{~W}$ power supply structure is open at a plant site, the realized UPQC can play out the electrical cable compensation despite when the presented single-arrange burdens require the fair-minded conduit to work.

In the feasibility of the UPQC-based 3P4W assignment structure was surveyed unmistakably by techniques for reenactment results, this paper expects to use the twofold reimbursing strategy use, with its innate ideal conditions, to achieve the going with purposes: I) smother load symphonious flows; ii) compensate load responsive power; iii) reimburse burden unbalances; iv) repay utility voltage unbalances; v) spread utility consonant voltages; and vi) direct the yield voltages.

\section{II.UPQC TOPOLOGY DESCRIPTION}

The UPQC topology used to realize the twofold pay strategy presented in this paper is showed up in Fig.4.1. It is incorporated both Three-Leg and Four-Leg converters having a comparable DC-interface.

The UPQC is related between a $3 \mathrm{P} 3 \mathrm{~W}$ power supply movement structure and a $3 \mathrm{P} 4 \mathrm{~W}$ plant site made out of a couple of sorts of three-phase and single-arrange loads. It is acknowledged that the single-organize burdens use the impartial conductor to work. For this circumstance, a 3P4W apportionment structure is basic, which is made out of three power conductors and an unprejudiced conductor to feed the stores. Therefore, as can be noted in the UPQC-based 3P4W allotment structure showed up in Fig. 1, the fair current goes through the wire channel related with the fourth leg of the shunt 4-Leg PWM converter.

The 4-Leg PWM converter was picked to go about as the shunt APF, in light of the way that it can work with lower DC-associate voltage abundancy when stood out from the 3-Leg PWM split-capacitor topology [2], [15]. Likewise, the 3-Leg split-capacitor topology requires an additional control hover to reimburse its regular DC-interface capacitor voltage unbalances. The power rating of the devices that structure its fourth leg is lessened, in light of the way that the present that courses through the unprejudiced conductor a great part of the time is low.

\section{A. Dual Compensation Principle}

In order to make the information flows sinusoidal, counterbalance and in stage with the utility voltages, in the twofold compensating methodology, the plan of PWM converter is controlled to fill in as a sinusoidal current source. For this condition, its impedance must be satisfactorily high to isolate the symphonious streams made by the non-straight loads. Then again, the parallel PWM converter in like way makes the yield voltages sinusoidal, adjusted, directed and in stage with the utility voltages. All things considered, it is controlled to fill in as a sinusoidal voltage source, to such a degree, that its impedance must be satisfactorily low to ingest the stack symphonious flows

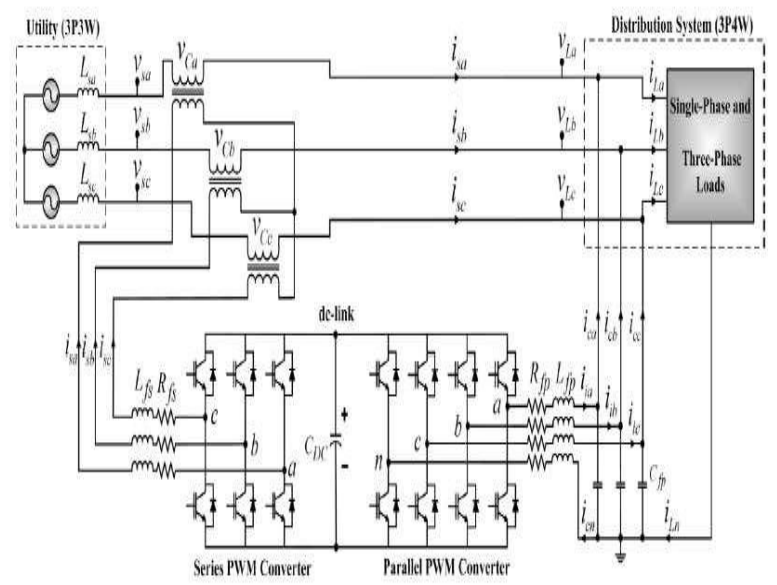

Fig. 1. 3 P4W dispersion framework dependent on UPQC topology associated with 3P3W power framework arrange

Since the course of action and parallel converters have high and low impedances, independently, the stack consonant ebbs and flows stream typically through the parallel converter. In addition, compensation for weight unbalances is ensured by controlling the course of action converter to seek after sinusoidal and balanced references with the objective that the negative and zero gathering parts are changed.

\section{III.MODELING OF SERIES AND PARALLEL CONVERTERS}

\section{A. Series Converter Forming}

The state-space framework and the exchange elements of the arrangement converter in the dq-tomahawks are acquired dependent on a numerical model. The demonstrating is practiced thinking about that every single included inductance and protections are indistinguishable, as pursues:

$L f s a=L f s b=L f s c=L f s$ and

$R f s a=R f s b=R f s c=R f s$.

By methods for Fig. 1, the conditions that speak to the framework are given by (1) and (2).

$$
\begin{aligned}
& u_{s a b_{\_} p w m}=v_{L f s a}+v_{R f s a}+v_{C a b}-v_{R f s b}-v_{L f s b} \\
& u_{s b c_{-} p w m}=v_{L f s b}+v_{R f s b}+v_{C b c}-v_{R f s c}-v_{L f s c}
\end{aligned}
$$

where: $u s a b \_p w m$ and usbc_pwmare the particular PWM voltages. 
From the equations usd_pwm and usq_pwm, the state-space condition is given by

$$
\dot{x}_{s d q}(t)=A_{s d q} \cdot x_{s d q}(t)+B_{s d q} \cdot u_{s d q}(t)+F_{s d q} \cdot w_{s d q}(t)
$$

where:

$$
\begin{aligned}
& \dot{x}_{s d q}(t)=\left[\begin{array}{c}
\frac{d i_{s d}}{\mathrm{dt}} \\
\frac{d i_{s q}}{\mathrm{dt}}
\end{array}\right] ; x_{s d q}(t)=\left[\begin{array}{l}
i_{s d} \\
i_{s q}
\end{array}\right] ; u_{s d q}=\left[\begin{array}{l}
u_{s d \_p w m} \\
u_{s q_{\_} p w m}
\end{array}\right] ; \\
& w_{s d q}(t)=\left[\begin{array}{cc}
v_{C d} \\
v_{c q}
\end{array}\right] ; A_{s d q}=\left[\begin{array}{cc}
-\frac{R_{f s}}{L_{f s}} & \omega \\
-\omega & -\frac{R_{f s}}{L_{f s}}
\end{array}\right] ; B_{s d q}=\frac{1}{3 L_{f s}}\left[\begin{array}{cc}
1 & 0 \\
0 & 1
\end{array}\right] \\
& F_{s d q}=\frac{1}{3 L_{f s}}\left[\begin{array}{cc}
-1 & 0 \\
0 & -1
\end{array}\right] .
\end{aligned}
$$

Hence, in view of Fig. 2(a), the exchange elements of the shut circle framework can be spoken to by (4), where $K p(d$, $q)$ and $K i s(d, q)$ are the corresponding and basic controller gains, and is $(d, q) *(\mathrm{~s})$ speaks to the persistent current references in the $d$-q organizes

$$
\frac{i_{s(d, q)}(s)}{i_{S(d, q)}^{*}(s)}=\frac{X_{1}\left(K p_{s(d, q)} s+K i_{s(d, q)}\right)}{L_{f s} s^{2}+\left(R_{f s}+X_{1} K p_{s(d, q)}\right) s+X_{1} K i_{s(d, q)}}
$$

where: $X 1=K P W M V D C$

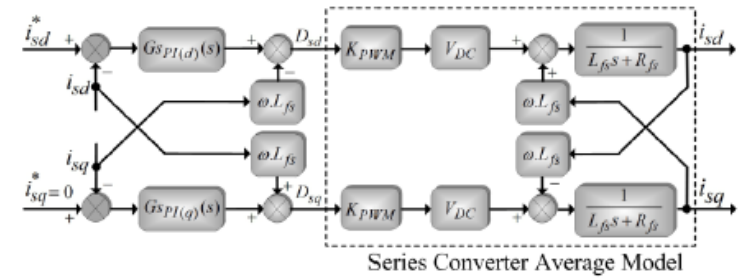

(a)

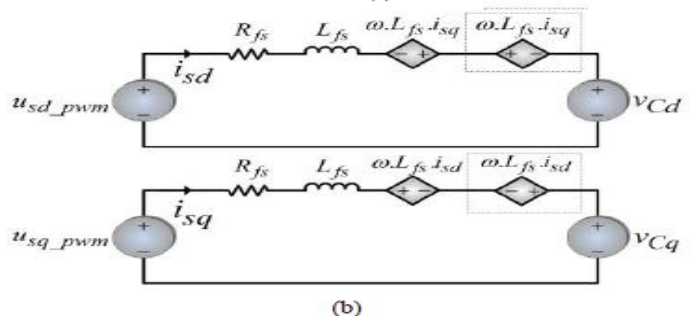

Fig. 2. Sequence converter: (a) Signal flow graph of the current regulators and average prototypical; (b) Ideal of the uncoupled system in SRF dq-axes.

\section{B. Parallel Converter Forming}

The state-space framework and exchange elements of the parallel converter in the dq0-tomahawks are acquired dependent on a numerical model. The displaying is cultivated thinking about that every included inductance, protections and capacitances are indistinguishable, as pursues:

$L f p a=L f p b=L f p c=L f p n=L f P$;

$R f p a=R f p b=R f p c=R f p n=R f p$, and

$C f p a=C f p b=C f p c=C f p$.

By methods for Fig. 1, the conditions that speak to the framework are given by (5), (6) and (7), as pursues:

where: upan_pwm,upbn_pwm, and upcn_pwm are the individual PWM voltages
The capacitor flows of the yield channels (iCfpa, iCfpb, and $i C f p$ ) are given by:

whereiia, iib and iic are the flows of the inductors, and $i c a, i c b$ and $i c c$ are the yield flows of the parallel converter.

Considering the PWM converter voltages of the parallel synchronous turning outline

$$
\begin{aligned}
& u_{p a n_{-} p w m}=R_{f p a} . i_{i a}+L_{f p a} \frac{d i_{i a}}{d t}+v_{L a}+L_{f p n} \frac{d i_{c n}}{d t}+R_{f p n} . i_{c n} \\
& u_{p b n_{\_} p w m}=R_{f p b} \cdot i_{i b}+L_{f p b} \frac{d i_{i b}}{d t}+v_{L b}+L_{f p n} \frac{d i_{C n}}{d t}+R_{f p n} . i_{c n} \\
& u_{p c n_{-} p w m}=R_{f p c} \cdot i_{i c}+L_{f c c} \frac{d i_{i c}}{d t}+v_{L c}+L_{f p n} \frac{d i_{C n}}{d t}+R_{f p n} . i_{c n}
\end{aligned}
$$

where: $u p a n \_p w m, u p b n \_p w m$, and $u p c n \_p w m$ are the respective $\mathrm{PWM}$ voltages.

The capacitor currents of the output filters (iCfpa, iCfpb, and ) are given by:

$$
\begin{aligned}
& i_{C f p a}=C_{f p a} \frac{d v_{L a}}{d t}=i_{i a}-i_{c a} \\
& i_{C f p b}=C_{f p b} \frac{d v_{L b}}{d t}=i_{i b}-i_{c b} \\
& i_{C f p c}=C_{f p c} \frac{d v_{L c}}{d t}=i_{i c}-i_{c c}
\end{aligned}
$$

whereiia, iib and iic are the currents of the inductors, and $i c a$, icb and icc are the output currents considering $(5)(6)(7)$ the state-space equation is found as:

$$
\begin{gathered}
\dot{x}_{p d q 0}(t)=A_{p d q 0} \cdot x_{p d q 0}(t)+B_{p d q 0} \cdot u_{p d q 0}(t) \\
+F_{p d q 0} \cdot w_{p d q 0}(t)
\end{gathered}
$$

where:

$$
\begin{aligned}
& \dot{x}_{p d q 0}(t)=\left[\begin{array}{llllll}
\frac{d i_{i d}}{\mathrm{dt}} & \frac{d i_{i q}}{\mathrm{dt}} & \frac{d i_{i 0}}{\mathrm{dt}} & \frac{d v_{L d}}{\mathrm{dt}} & \frac{d v_{L q}}{\mathrm{dt}} & \frac{d v_{L 0}}{\mathrm{dt}}
\end{array}\right]^{T} ; \\
& x_{p d q 0}(t)=\left[\begin{array}{llllll}
i_{i d} & i_{i q} & i_{i 0} & v_{L d} & v_{L q} & v_{L 0}
\end{array}\right]^{T} ; \\
& u_{p d q 0}\left[\begin{array}{l}
u_{p d_{-} p w m} \\
u_{p q_{-} p w m} \\
u_{p 0_{-} p w m}
\end{array}\right] ; w_{p d q 0}\left[\begin{array}{l}
i_{C f p d} \\
i_{C f p q} \\
i_{C f p 0}
\end{array}\right] ; \\
& \begin{aligned}
A_{p d q \mathrm{O}} & =\left[\begin{array}{cccccc}
-\frac{R_{f p}}{L_{f p}} & \omega & 0 & -\frac{1}{L_{f p}} & 0 & 0 \\
-\omega & -\frac{R_{f p}}{L_{f p}} & 0 & 0 & -\frac{1}{L_{f p}} & 0 \\
0 & 0 & -\frac{R_{f p}}{L_{f p}} & 0 & 0 & -\frac{1}{4 L_{f p}} \\
\frac{1}{C_{f p}} & 0 & 0 & 0 & \omega & 0 \\
0 & \frac{1}{C_{f p}} & 0 & -\omega & 0 & 0 \\
0 & 0 & \frac{1}{C_{f p}} & 0 & 0 & 0
\end{array}\right] \\
B_{p d q O} & =\left[\begin{array}{ccc}
\frac{1}{L_{f p}} & 0 & 0 \\
0 & \frac{1}{L_{f p}} & 0 \\
0 & 0 & \frac{1}{4 L_{f p}} \\
0 & 0 & 0 \\
0 & 0 & 0 \\
0 & 0 & 0
\end{array}\right] F_{p d q 0}=\left[\begin{array}{ccc}
0 & 0 & 0 \\
0 & 0 & 0 \\
-\frac{1}{C_{f p}} & 0 & 0 \\
0 & -\frac{1}{C_{f p}} & 0 \\
0 & 0 & -\frac{1}{C_{f p}}
\end{array}\right] .
\end{aligned}
\end{aligned}
$$

In this manner, in light of [11], the parallel converter normal model spoke to as a sign stream chart is appeared in the specked region of Fig. 3(a).

Along these lines, in view of Fig. 3(a), the exchange elements of the shut circle framework can be spoken to by [12] and [13], where $\operatorname{Kpp}(d, q), \operatorname{Kip}(d, q)$ and $\operatorname{Kip}(0)$ are the relative and vital increases of the controllers (external voltage control circle), $K p p i(d, q)$ and $K p p i(0)$ are the corresponding additions (inward current control circle), and $v L(d, q, 0) *(\mathrm{~s})$ speaks to the nonstop 


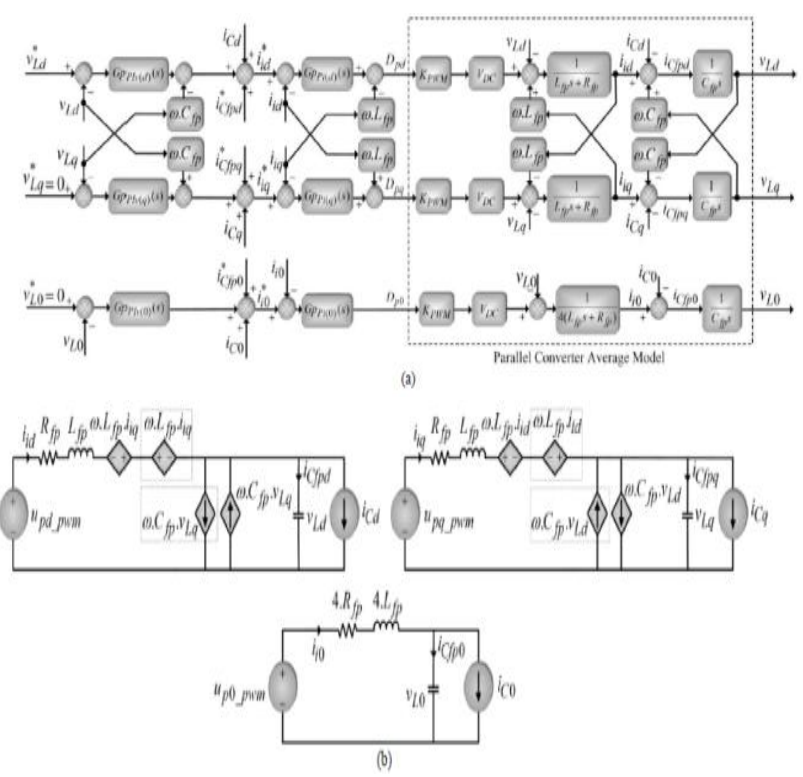

Fig. 3. Parallel converter: (a) Signal flow graph of the voltage controllers and average model; (b) Model of the uncoupled system in SRF dq0-axes.

The currents of the filter capacitors $i \operatorname{Cfp}(d, q, 0)$ shown in Fig. 3(a) are estimated considering the derivatives of the measured output voltages $(v L a, b, c)$ and the respective capacitances $(C f p a, b, c)[4]$.

$$
\begin{aligned}
& \frac{v_{L(d, q)}(s)}{v_{L(d, q)}^{*}(s)}=\frac{X_{1(d, q)} s^{2}+X_{2(d, q)} s+X_{3(d, q)}}{Y_{1(d, q)} s^{3}+Y_{2(d, q)} s^{2}+Y_{3(d, q)} s+Y_{4(d, q)}} \\
& \frac{v_{L(0)}(s)}{v_{L(0)}^{*}(s)}=\frac{X_{1(0)} s^{2}+X_{2(0)} s+X_{3(0)}}{Y_{1(0)} s^{3}+Y_{2(0)} s^{2}+Y_{3(0)} s+Y_{4(0)}}
\end{aligned}
$$

where:

$X 1(d, q)=K P W M V D C C f p K p p i(d, q)$;

$X 2(d, q)=K P W M V D C K p p i(d, q) K p p(d, q)$;

$X 3(d, q)=Y 4(d, q)=K P W M V D C K p p i(d, q) \operatorname{Kip}(d, q)$;

$Y 1(d, q)=C f p L f p$

$Y 2(d, q)=C f p(K P W M V D C K p p i(d, q)+R f p)$;

$Y 3(d, q)=K P W M V D C K p p i(d, q) K p p(d, q)+1$;

$X 1(0)=K P W M V D C C f p K p p i(0)$;

$X 2(0)=K P W M V D C K p p i(0) K p p(0)$;

$X 3(0)=Y 4(0)=K P W M V D C K p p i(0) K i p(0)$;

$Y 1(0)=4 C f p L f p$;

$Y 2(0)=C f p(K P W M V D C K p p i(0)+4 R f p)$;

$Y 3(0)=K P W M V D C K p p i(0) K p p(0)+4$.

\section{PROPOSED NEURAL NETWORK CONTROLLER AND MODEL OF ARTIFICIAL NEURAL NETWORK}

An Artificial Neural Network (ANN) is a data handling worldview that is motivated by the way organic sensory systems, for example, the cerebrum, process data. The key component of this worldview is the novel structure of the data preparing framework. It is made out of numerous exceptionally interconnected preparing components (neurons) working as one to take care of explicit issues. designed for a particular application, for example, design acknowledgment or information order, through a learning procedure. Learning in organic frameworks includes acclimations to the synaptic associations that exist between ANNs, similar to individuals, learn by precedent. An ANN is

the neurons. This is valid if there should be an occurrence of ANNs also. The fundamental structure square of every single organic cerebrum is a nerve cell, or a neuron as appeared in the Fig.5.

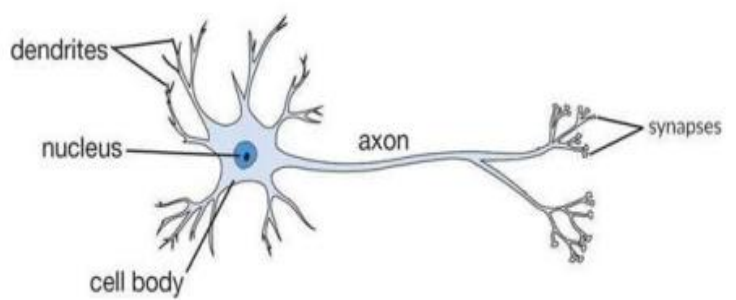

Fig. 5 A Biological Neuron

The model of Artificial neural system is appeared in fig. 3, which has info layer, concealed layer and yield layer. The info layer contains those units (fake neurons) which get contribution from the outside world on which system will learn, perceive about or generally process. Yield layer contains units that react to the data about how it's found out any undertaking. Concealed layers are in the middle of info and yield layers. The neuron has following parts: 1) Neuron: A neuron (or cell or a unit) is a self-sufficient preparing component. Neuron can be thought of a basic PC. The reason for every neuron is to get data from different neurons, perform moderately straightforward preparing of the joined data, and send the outcomes to at least one different neurons. For the most part, neurons are spoken to by circle or squares. 2) Layers: A layer is an accumulation of neurons that can be thought of as playing out some sort of regular capacities. These neurons are typically numbered by setting the numbers or letters by every neuron and are commonly accepted that no neuron is associated with another neuron in a similar layer.

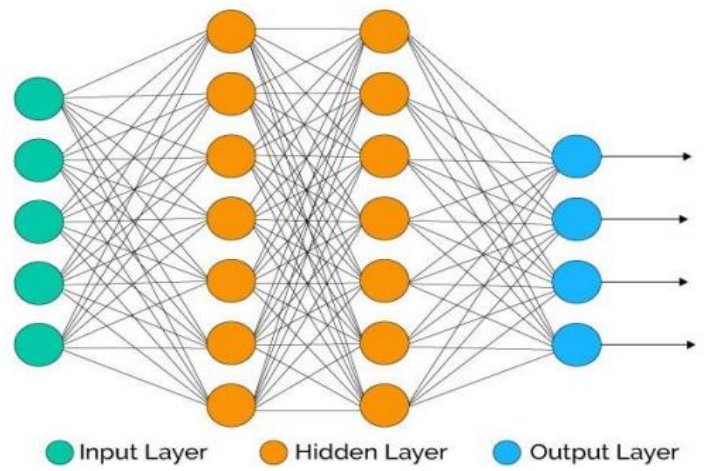

Fig. 5 Model of Artificial Neural Network

\section{V.SIMULATION RESULTS}

\section{a)EXISTING RESULTS}

Fig 5.1 and 5.2 shows the MATLAB/SIMULINK diagram of the system and Controller subsystem with PI controller, fig 5.3 shows line voltage fig 5.4 shows line current ,Fig 5.5 shows load current, fig 5.6 shows load voltage and fig 5.7 shows shunt converter current. Here the fault occurs in load current at time period $0.06 \mathrm{sec}$ to $0.18 \mathrm{sec}$ as shown in figure 5.5. The shunt current is injected to the load current in the time period $0.06 \mathrm{sec}$ to $0.018 \mathrm{sec}$ as shown in figure 5.7, finally we get the load current sinusoidal wave shape. 


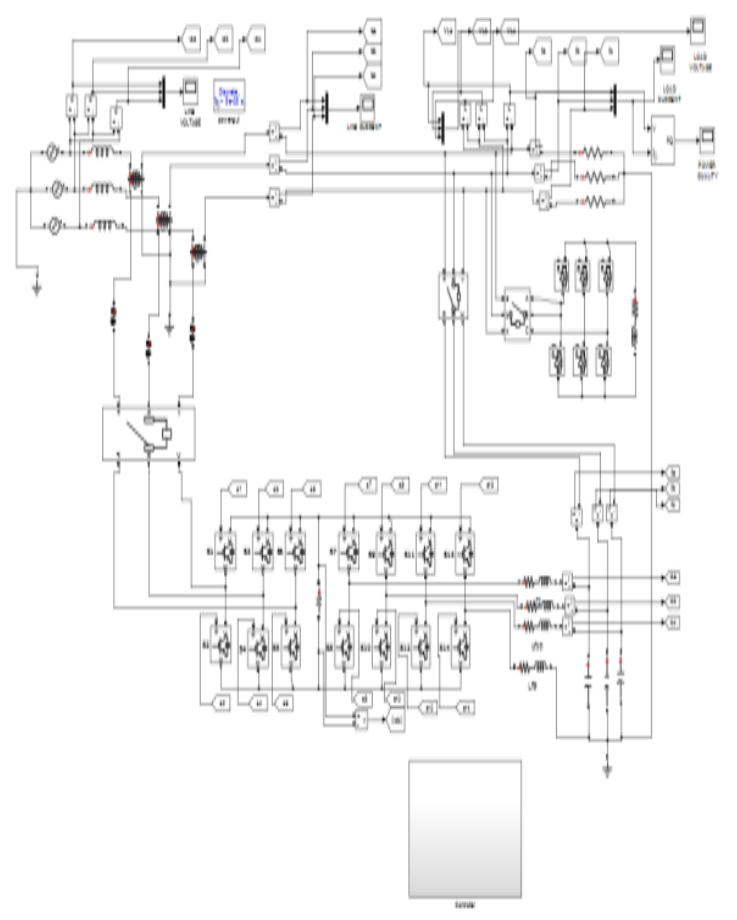

Fig 5.1 MATLAB/SIMULINK diagram of the system

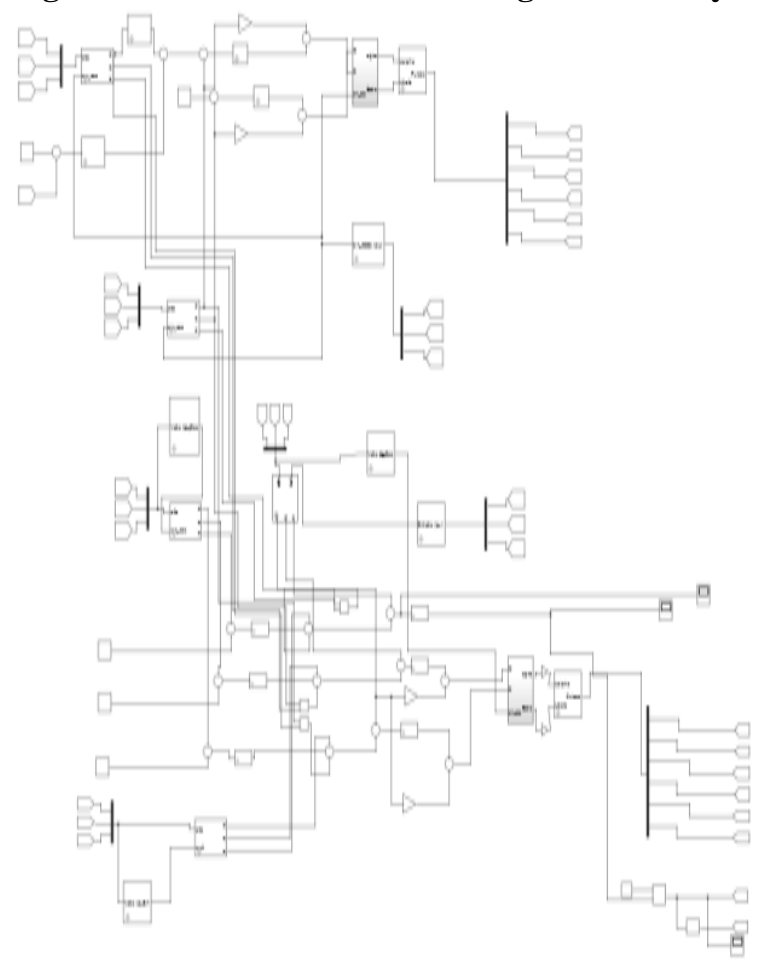

Fig 5.2 Controller subsystem

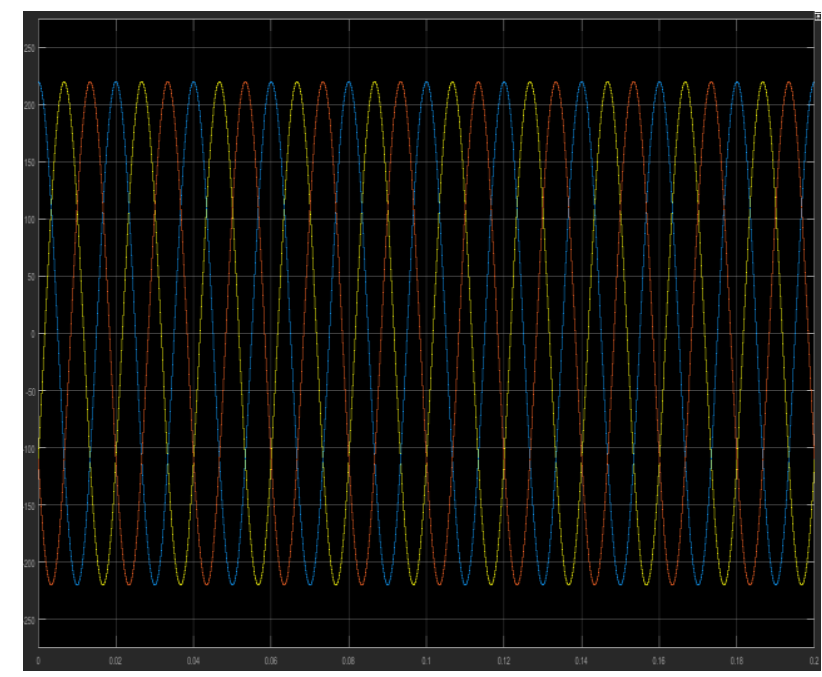

Fig 5.3 Line voltage

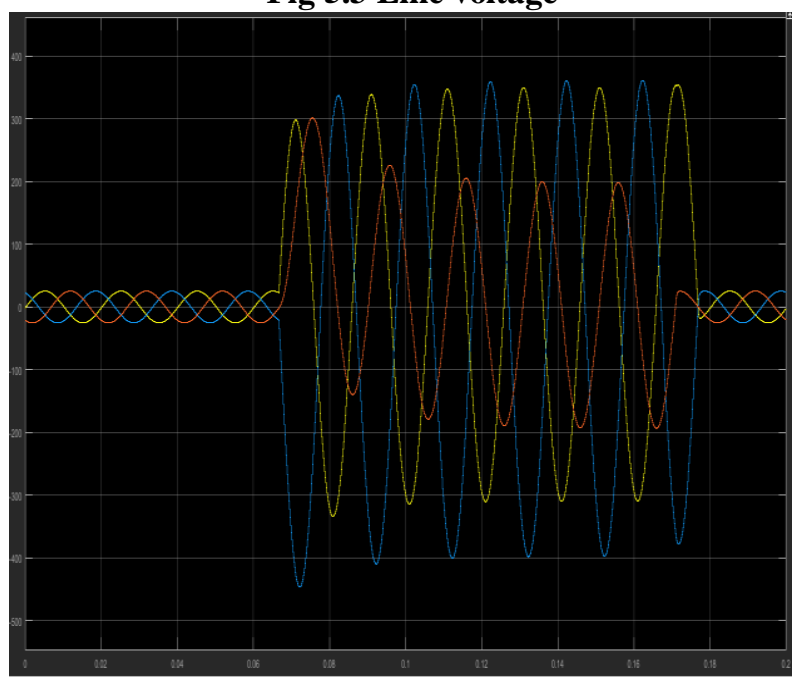

Fig 5.4 Line current

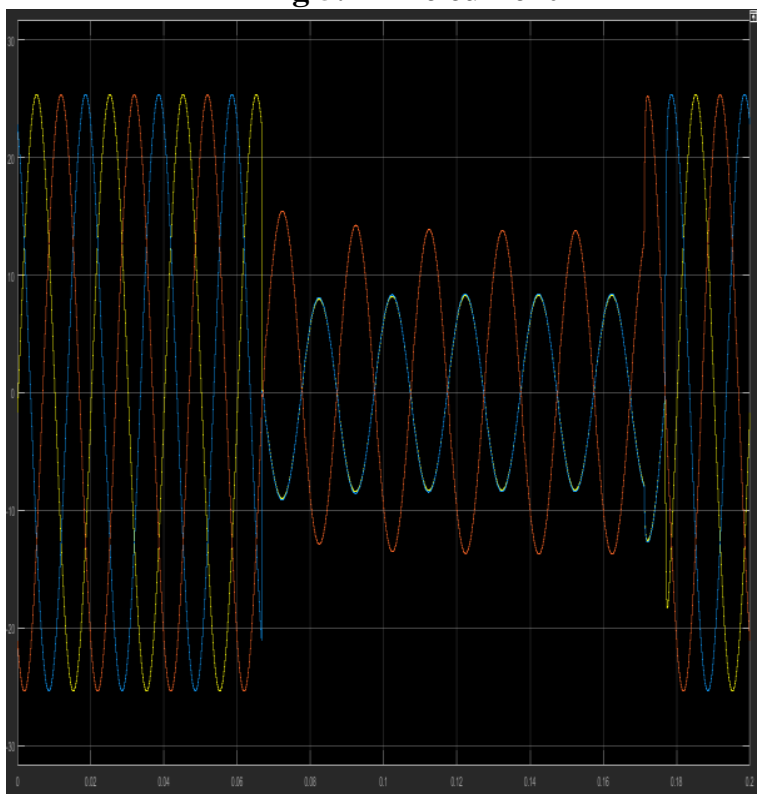

Fig5.5 Load current

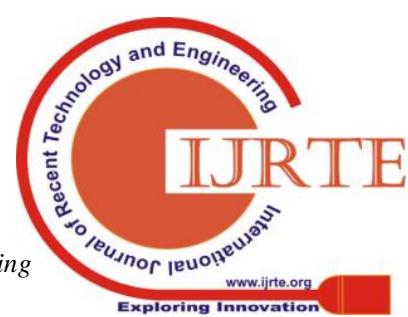


Power Quality Enhancement of Three Phase Four Wire UPQC in Distribution System using Neural Network

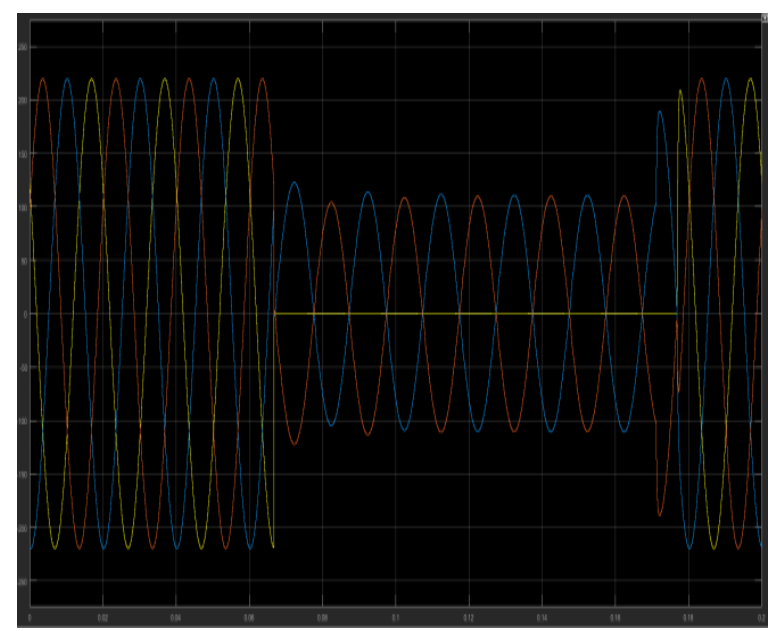

Fig 5.6Load voltage

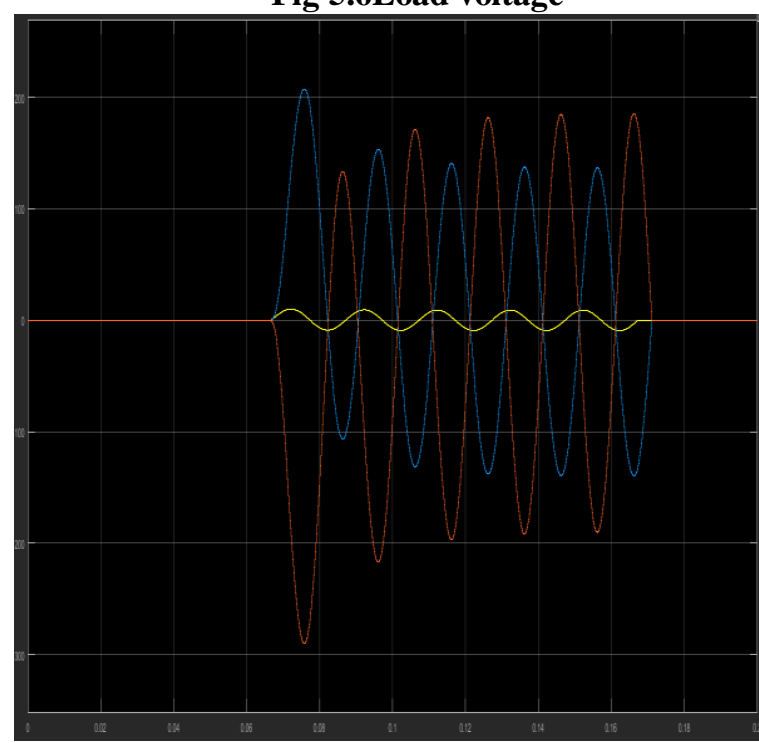

Fig 5.7 Shunt converter current

b) EXTENSION RESULTS WITH NEURAL NETWORK CONTROLLERS

Fig 5.8 shows proposed controller subsystem with neural network controller, fig 5.9 shows line voltage fig 5.10 shows line current, fig 5.11 shows load current, fig 5.12 shows load voltage. Here the fault occurs in load current at time period $0.06 \mathrm{sec}$ to $0.2 \mathrm{sec}$ as shown in figure 5.11. The shunt current is injected to the load current in the time period $0.06 \mathrm{sec}$ to 0.2 sec.

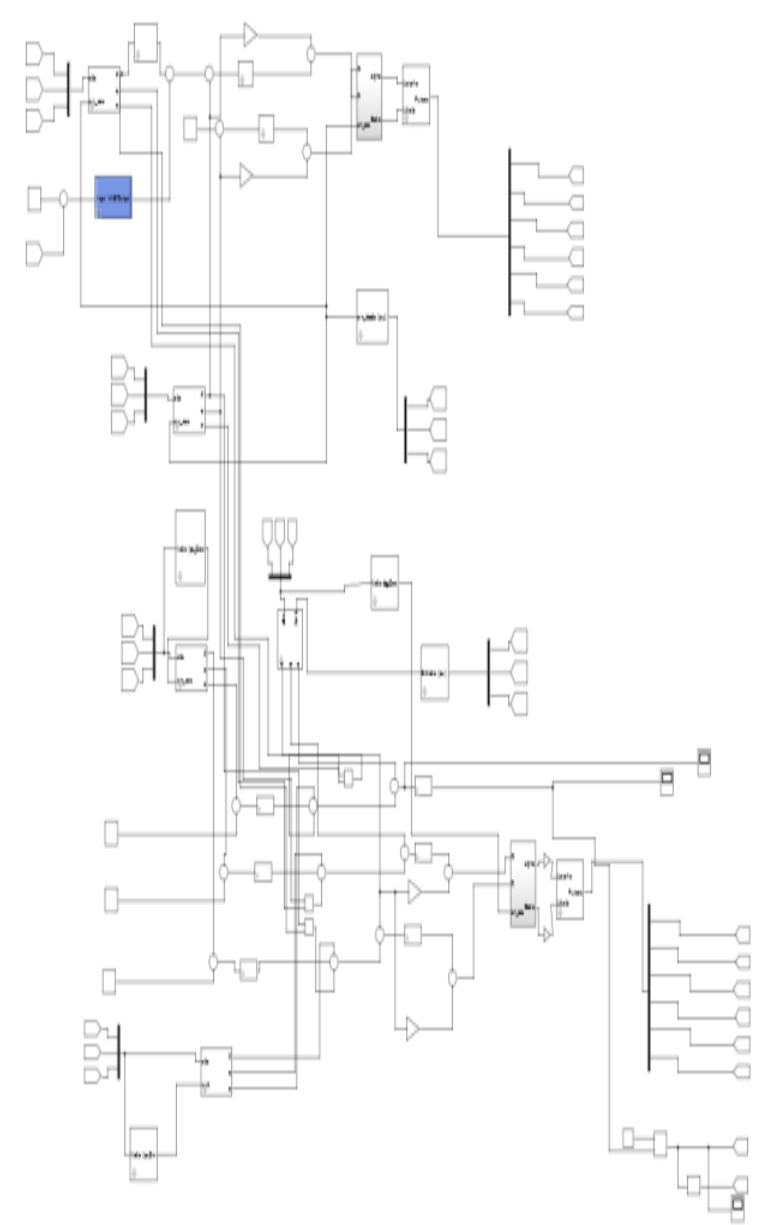

Fig 5.8 Proposed Controller subsystem

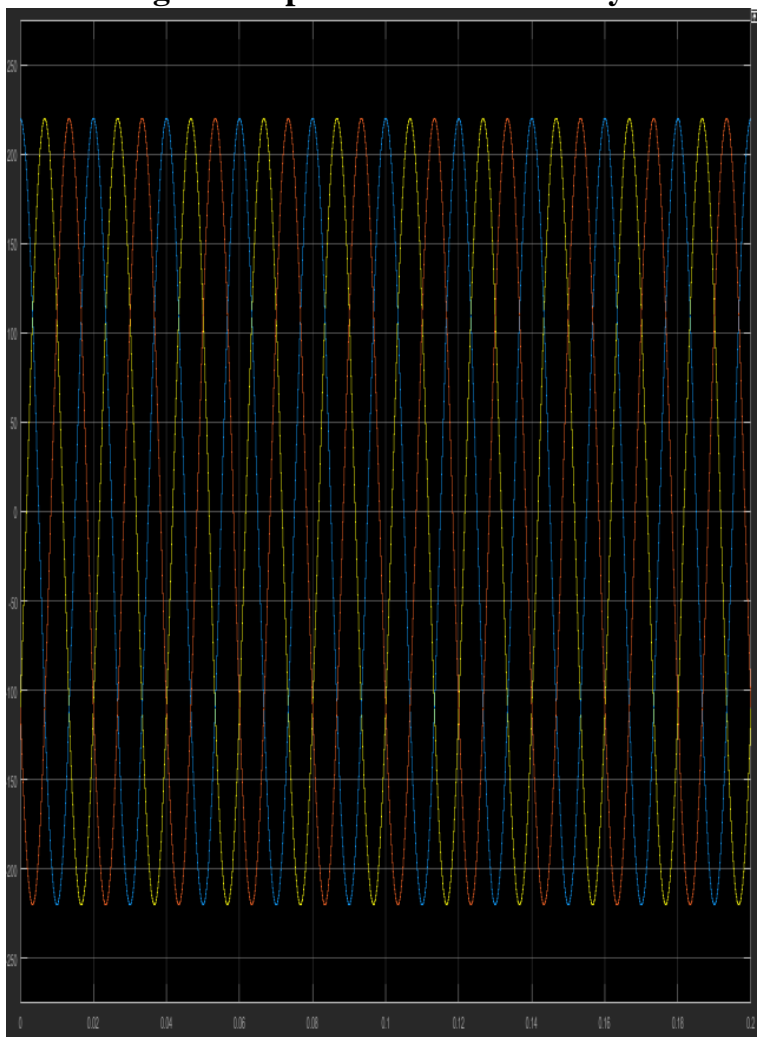

Fig 5.9 Line voltage

\section{Published By:}




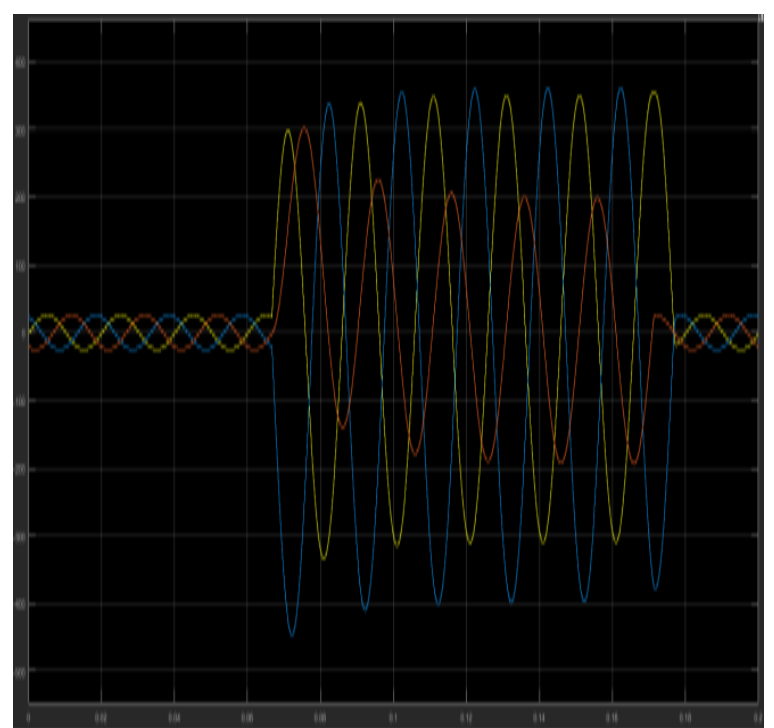

Fig 5.10 Line current

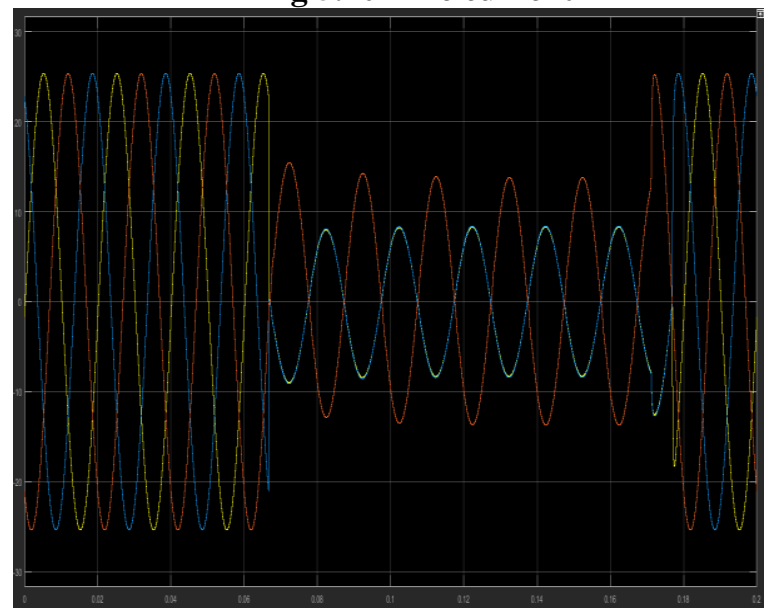

Fig5.11 Load current

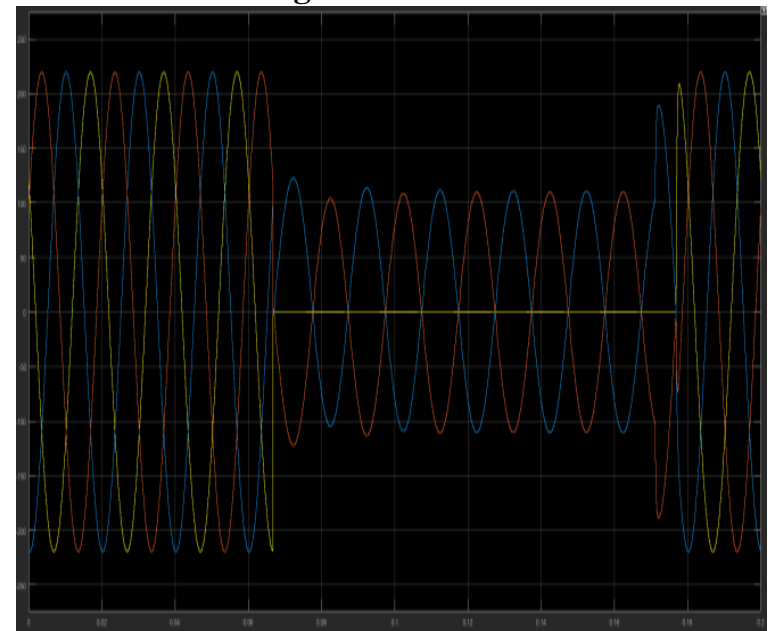

Fig 5.12 Load voltage

Fig 5.13 shows the line current THD (0.32\%) with PI controller it will reduced to $0.25 \%$ by using neural network controller as shown in fig 5.14. Fig 5.15 shows the load current THD (1.41\%) with PI controller and it will reduce to $1.16 \%$ by using NN controller as shown in fig 5.16.

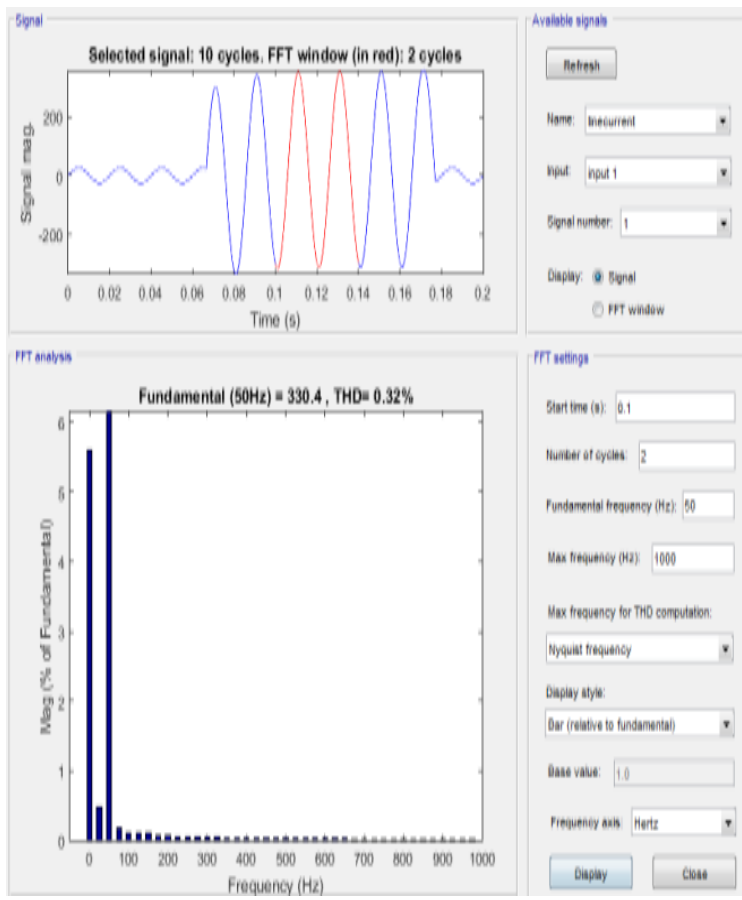

Fig 5.13 Line current THD $(0.32 \%)$ with PI controller
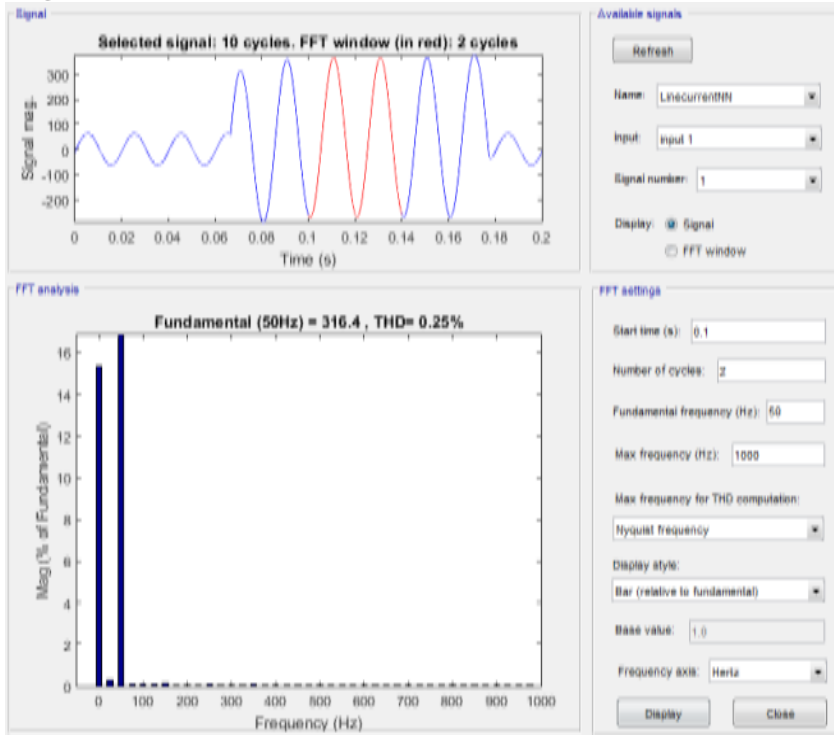

Fig 5.14 Line current THD $(0.25 \%)$ with proposed NN controller

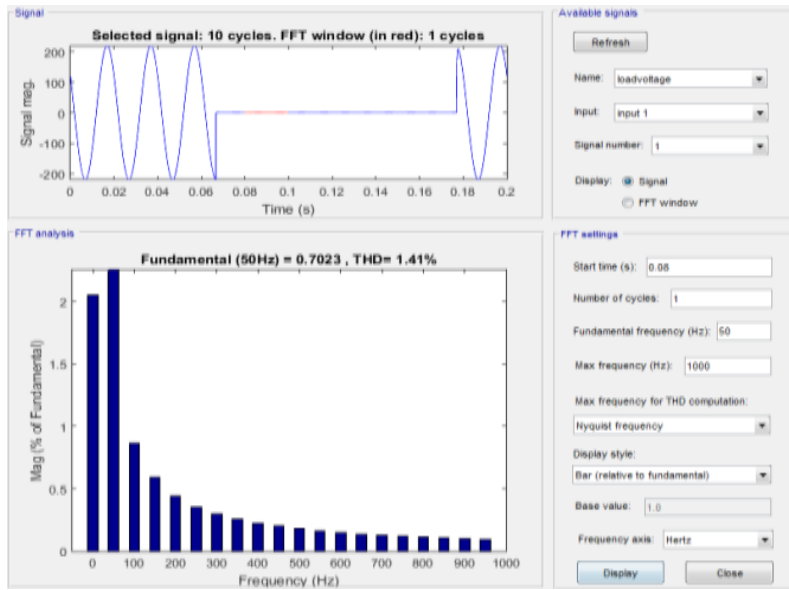

Fig 5.15 Load current THD (1.41\%) with existing PI controller

Published By:

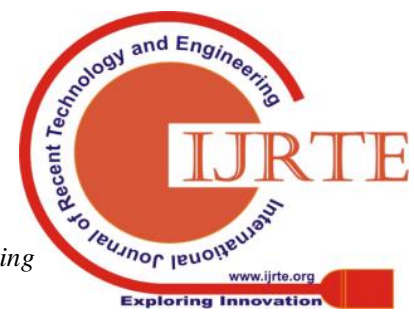




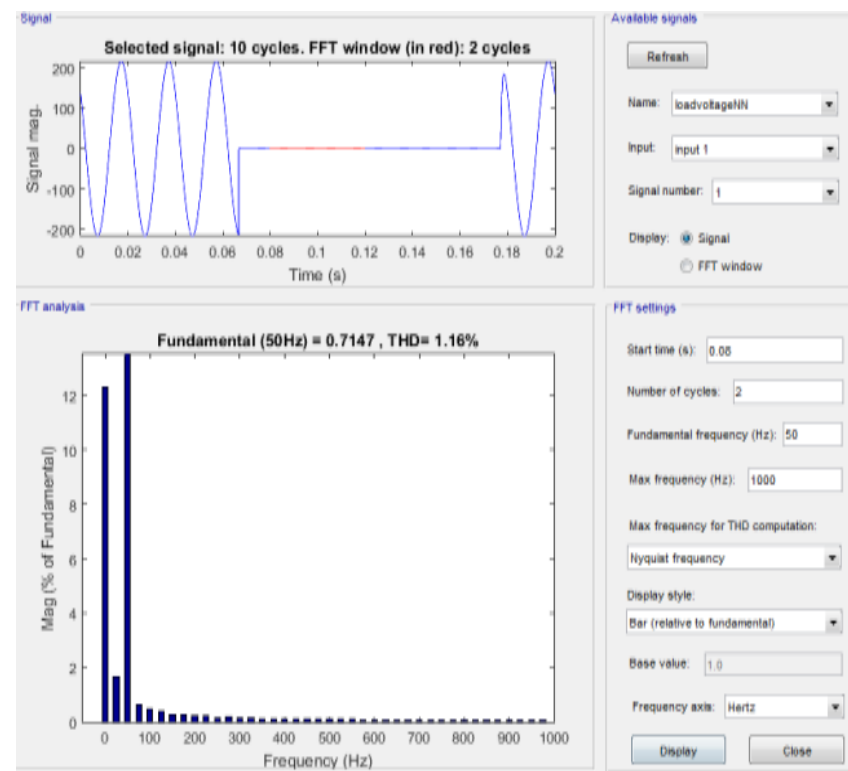

Fig 5.16 Load current THD (1.16\%) with proposed NN controller

\section{CONCLUSION}

Another present decay procedure, in view of recurrence area and SRF hypothesis, with roundabout current control and decreased number of current sensors for organized particular remuneration of various power characteristics and their blends has been examined for the shunt APF of three stage four-wire UPQC. A control methodology dependent on SRF hypothesis with neural system controller is connected for the control of the arrangement APF of UPQC. The watched presentation of the UPQC has exhibited the capacity of the proposed control system to specifically repay the music, the all-out source current harmonics, uneven stacking, in light of need to regard the constrained power limit of VSIs utilized for the shunt and arrangement APFs associated consecutive with normal DC connect capacitor. Moreover, by relief of client produced sounds just, the duty of the utility and clients at the PCC is ascribed. It is additionally seen that the proposed control plan has a quick reaction and can keep up the voltage and current music levels, along these lines adjusting to IEEE principles. The control plan of shunt APF has the benefit of adaptability in the determination of the power quality improvement for which the reference might be registered. Notwithstanding this the shunt APF remunerates the current based symphonious twists even under mutilated utility voltages, henceforth the task of shunt and arrangement APF are autonomous of one another. The reenactment results are appearing with PI and NN controller THDs.

\section{REFERENCES}

1. Rodrigo Augusto Modesto, Sérgio Augusto Oliveira da Silva, Member, IEEE, Azauri Albano de Oliveira Júnior, and ViníciusDário Bacon "Versatile Unified Power Quality Conditioner Applied to Three-Phase Four-Wire Distribution Systems Using aDualControlStrategy"10.1109/TPEL.2015.2487867,IEE E Transactions on Power Electronics.

2. M. Oprisan and S. Pneumaticos, "Potential for electricity generation from emerging renewable sources in Canada," in Proc. IEEE EIC Climate Change Technol. Conf., May 2006, pp. 1-10.
3. G. Petrone, G. Spagnuolo, R. Teodorescu, M Veerachary, and M. Vitelli, "Reliability issues in photovoltaic power processing systems,"IEEE Trans. Ind. Electron., vol. 55, no. 7, pp. 2569-2580, Jul. 2008.

4. S. Jain and V. Agarwal, "A single-stage grid connected inverter topology for solar PV systems with maximum power point tracking," IEEE Trans. Power Electron., vol. 22, no. 5, pp. 1928-1940, Jul. 2007.

5. F. Katiraei and J. Aguero, "Solar PV integration challenges," IEEE Power Energy Mag., vol. 9, no. 3, pp. 62-71, May-Jun. 2011.

6. S. H. Ko, S. Lee, H. Dehbonei, and C. Nayar, "Application of voltageand current-controlled voltage source inverters for distributed generation systems," IEEE Trans. Energy Convers., vol. 21, no. 3, pp. 782-792, Sep. 2006.

7. F. Blaabjerg, Z. Chen, and S. Kjaer, "Power electronics as efficient interface in dispersed power generation systems," IEEE Trans. Power Electron., vol. 19, no. 5, pp. 1184-1194, Sep. 2004.

8. J. Carrasco et al., "Power-electronic systems for the grid integration of renewable energy sources: A survey," IEEE Trans. Ind. Electron., vol. 53, no. 4, pp. 1002-1016, Jun. 2006.

9. T. Esram and P. Chapman, "Comparison of photovoltaic array maximum power point tracking techniques," IEEE Trans. Energy Convers., vol. 22, no. 2, pp. 439-449, Jun. 2007.

10. S. Jain and V. Agarwal, "Comparison of the performance of maximum power point tracking schemes applied to single-stage grid-connected photovoltaic systems," IET Electr. Power Appl., vol. 1, no. 5, pp. 753-762, Sep. 2007.

11. R. Mastromauro, M. Liserre, and A. Dell'Aquila, "Control issues in single-stage photovoltaic systems: MPPT, current and voltage control," IEEE Trans. Ind. Informat., vol. 8, no. 2, pp. 241-254, May 2012.

12. R. Varma, B. Das, I. Axente, and T. Vanderheide, "Optimal 24-hr utilization of a PV solar system as STATCOM(PV-STATCOM) in a distribution network," in Proc. IEEE Power Energy Soc. Gener. Meet., Jul. 2011, pp. $1-8$.

13. A. Yazdani et al., "Modeling guidelines and a benchmark for power system simulation studies of three-phase single-stage photovoltaic systems," IEEE Trans. Power Del., vol. 26, no. 2, pp. 1247-1264, Apr. 2011.

14. F. Delfino, G. Denegri, M. Invernizzi, and R. Procopio, "A control algorithm for the maximum power point tracking and the reactive power injection from grid-connected PV systems," in Proc. IEEE Power Energy Soc. Gener. Meet., Jul. 2010, pp. 1-7.

15. L. Wang and Y.-H. Lin, "Dynamic stability analyses of a photovoltaic array connected to a large utility grid," in Proc. IEEE Power Eng. Soc. Winter Meet., Jan. 2000, vol. 1, pp. 476-480.

16. B. Tamimi, C. Canizares, and K. Bhattacharya, "Modeling and performance analysis of large solar photo-voltaic generation on voltage stability and inter-area oscillations," in Proc. IEEE Power Energy Soc. Gener. Meet., Jul. 2011, pp. 1-6.

17. W. Du, H. Wang, and R. Dunn, "Power system small-signal oscillation stability as affected by large-scale PV penetration," in Proc. IEEE Int. Conf. SUPERGEN, Apr. 2009, pp. 1-6. 
18. S. Balathandayuthapani, C. Edrington, S. Henry, and J. Cao, "Analysis and control of a photovoltaic system: Application to a high penetration case study," IEEE Syst. J., vol. 6, no. 2, pp. 213-219, Jun. 2012.

19. A.Yazdani and P. Dash, "A control methodology and characterization of dynamics for a photovoltaic (PV) system interfaced with a distribution network," IEEE Trans. Power Del., vol. 24, no. 3, pp. 1538-1551, Jul. 2009.

20. Bo, Z.Q., Weller, G., Redfern, M.A.: 'Accurate fault location technique for distribution system using faultgenerated high-frequency transient voltage signals', IEE Proceedings of Generation, Transmission andDistribution, 1999, 146, (1), pp. 73-79

21. Chunju, F., Li, K.K., Chan, W.L., et al.: 'Application of wavelet fuzzy neural network in locating single line toground fault (SLG) in distribution lines', Electrical Power and Energy Systems, 2007, 29, (6), pp. 497-5031

22. Xinzhou, D., Zhongxing, G., Yaozhong, G., et al.: 'Application of wavelet transform in power system faultsignal analysis', Proceedings of the CSEE, 1997, 17, (6), pp. 421-424

23. Qingquan, J., Lianguang, L., Yihan, Y.: 'Abrupt change detection with wavelet for small current fault relaying',Proceedings of the CSEE, 2001, 21, (10), pp. 78-82

24. Hanninen, S., Lehtonen, M., Hakola, T., et al.: 'Characteristics of earth faults in power systems with a compensated or an unearthed neutral', IEE 14th International Conference and Exhibition on ElectricityDistribution, Jun. 1997, pp. 16/1-16/5

25. Sanjit, K. M.: 'Digital Signal Processing : A Computer-Based Approach ', (The McGraw-HillCompanies, New York, 2000, 4th edn. 2011)

26. Brian S. E., Sabine L., Morven L., et al.: 'Cluster Analysis' (John Wiley Sons, Ltd, Hoboken, 1993,5th edn. 2011.

27. G. Devadasu, Dr. M. Sushama "A Multilevel Diode Clamped SVPWM Based Interline Dynamic Voltage Restorer with Sag \& Swell Limiting Function" International Journal of Electronics Engineering Research (IJEER). Volume 9, Number 5, pp. 751-760, 2017.

28. A.Malathi, Muthubalaji. S., M.Divyacharitha , 'An Improved Power Quality Solution for Power System using Custom Power Devices" International Journal of Recent Technology and Engineering (IJRTE), vol.8 ,No 1, pp. 2005-2011, 2019 